\title{
A NECESSIDADE DE PROTEÇÃO INTERNACIONAL NO ÂMBITO DA MIGRAÇÃO
}

\author{
Liliana Lyra Jubilut e Silvia Menicucci. O. S. Apolinário
}

THE NEED OF INTERNATIONAL PROTECTION IN THE AREA OF MIGRATION

\section{RESUMO}

TEM-SE DISCUTIDO A RESPEITO DO SURGIMENTO DO DIREITO InTERnACIONAL da MigraÇão. ALÉm da aUsênCIA dE AUTONOMIA, É PRECISO RESSALTAR QUE AS DIFERENTES SITUAÇÕES DE MIGRAÇ̃̃ES DEMANDAM DIFERENTES PROTEC̣ÕES. NESSE SENTIDO, O ARTIGO ABORDA A DIFERENÇA CLÁSSICA ENTRE MIGRAÇÕES FORÇADAS E VOLUNTÁRIAS E EXPLORA O ESTADO ATUAL DA PROTECÃO INTERNACIONAL EXISTENTE PARA O CASO DOS MIGRANTES TRABALHADORES, DOS REFUGIADOS E DAS PESSOAS EM CONDICÃO ANÁLOGA À DE REFUGIADO: OS DESLOCADOS INTERNOS, OS DESLOCADOS POR QUESTÕES AMBIENTAIS E OS DESLOCADOS EM RAZÃO DA VIOLACC̆O DE DIREITOS ECONÔMICOS, SOCIAIS E CULTURAIS E DE DESENVOLVIMENTO. A AUSÊNCIA OU INSUFICIÊNCIA DE PREVISÃO DE PROTEÇĀO ADEQUADA NO DIREITO INTERNACIONAL PARA ALGUMAS DAS SITUACÕES MENCIONADAS FAZ QUE HAJA UMA BUSCA POR REFÚGIO EM SITUAÇÕES ÀS QUAIS ISSO NÃO SE APLICA. A SOLUCÃO, NOS DIAS ATUAIS, NÃO ESTÁ NA CRIACÃO DE UM NOVO RAMO DO DIREITO, MAS SIM NA APLICAÇ̃̃O DAS NORMAS DE DIREITO INTERnACIONAL DOS DiREITOS HUMANOS PARA OFERECER A PROTEÇÃO NOS CASOS NÃO ESPECIFICAMENTE REGULADOS EM ÂMBITO INTERNACIONAL.

\section{PALAVRAS-CHAVE}

PROTEÇÃO; MIGRAÇÃO; DIREITO INTERNACIONAL; MIGRANTES: REFUGIADOS; APÁTRIDAS; DESLOCADOS.

\begin{abstract}
THE EMERGENCE OF AN INTERNATIONAL LAW OF MIGRATION HAS BEEN DISCUSSED. APART FROM THE LACK OF AUTONOMY, IT IS RELEVANT TO HIGHLIGHT THAT THE DIFFERENT MIGRATION SITUATIONS DEMAND DIFFERENT KINDS OF PROTECTION. IN THIS SENSE, THIS PAPER PRESENTS THE CLASSIC DIFFERENCE BETWEEN FORCED AND VOLUNTARY MIGRATION, AND EXPLORE THE CURRENT STATE OF THE EXISTING INTERNATIONAL PROTECTION FOR WORKING MIGRANTS; REFUGEES AND OTHER PEOPLE IN SIMILAR SITUATIONS: INTERNALLY DISPLACED PEOPLE; DISPLACED PEOPLE DUE TO ENVIRONMENTAL REASONS AND DISPLACED PEOPLE DUE TO VIOLATION OF ECONOMIC, SOCIAL AND CULTURAL RIGHTS AND LACK OF DEVELOPMENT. THE INEXISTENCE OR INCIPIENCY OF ADEQUATE PROVISIONS OF PROTECTION IN INTERNATIONAL LAW FOR SOME OF THE AFOREMENTIONED SITUATIONS RESULTS IN REQUESTS FOR REFUGE WHEN THIS INSTITUTE DOES NOT APPLY. THE SOLUTION NOWADAYS DOES NOT LIE IN THE CREATION OF A NEW BRANCH OF LAW, BUT RATHER IN THE APPLICATION OF INTERNATIONAL HUMAN RIGHTS NORMS TO BRING PROTECTION IN THE CASES WHERE SPECIFIC INTERNATIONAL NORMS DO NOT EXIST.
\end{abstract}

\section{KEYWORDS}

PROTECTION; MIGRATION; INTERNATIONAL LAW; MIGRANTS; REFUGEES; STATELESS; DISPLACED.

\section{INTRODUÇÃO}

A análise jurídica da complexa temática da migração feita pela doutrina internacionalista tem demonstrado, nos últimos tempos, um esforço para sistematizar as normas de proteção internacional aplicadas às diferentes situações de migração, 
agrupadas sob o Direito Internacional de Migração (CHOLEWINSKI; PERRUCHOUD; MACDONALD, 2007). ${ }^{2}$ Essa proposta, na verdade, agrupa normas que usualmente são consideradas como parte do direito internacional dos direitos humanos, do direito internacional dos refugiados, do direito internacional humanitário, do direito internacional do trabalho, do direito internacional econômico e do direito internacional penal.

Há, pois, que se indagar a respeito da autonomia deste sugerido novo ramo do direito internacional, e do risco de se considerar as situações de migrantes forçados - tais como os refugiados e as pessoas forçadamente deslocadas, classicamente diferenciados dos migrantes (econômicos) em função das necessidades e demandas particulares derivadas de perseguições ou outras violações sérias, de que decorrem fortes obrigações jurídicas dos Estados de protegê-los - como sujeitas a um genérico direito internacional da migração. E, mais do que isso, deve-se indagar se o estabelecimento de um direito internacional da migração não obscurecerá as particularidades de cada tipo de migrante, em vez de aprimorar a proteção dos direitos humanos das pessoas em movimento (MCADAM, 2007).

Em face disso, o presente artigo busca definir, com respaldo na doutrina e no próprio direito internacional, quando possível, as principais situações de migrantes, a fim de verificar os instrumentos de proteção cabíveis e a necessidade de se ampliar a proteção internacional, respeitando-se as particularidades de cada grupo.

Assim, o objetivo não é exacerbar os aspectos técnicos das distinções entre os migrantes, mas, sim, a partir destas, verificar meios de se aprimorar a proteção internacional e, com isso, a proteção das pessoas em movimento.

\section{O CONTEXTO DA PROPOSIÇÃO DE UM DIREITO INTERNACIONAL DA MigraçÃo}

As migrações compõem parte da história da humanidade e constituem um fenômeno que cresce a cada dia. Estima-se que haja mais de 200 milhões de migrantes internacionais no mundo hoje, ${ }^{3}$ ou o equivalente a $3 \%$ da população mundial, e 26 milhões de deslocados internos. ${ }^{4}$ As migrações são um tema o qual engloba aspectos jurídicos, políticos, sociais e culturais; sendo inerentemente multidisciplinar e ensejando reações profundas nas diversas sociedades. De acordo com a Organização Internacional para Migrações:

Migration is one of the defining issues of the twenty-first century. It is now an essential, inevitable and potentially beneficial component of the economic and social life of every country and region. The question is no longer whether to have migration, but rather how to manage migration effectively so as to enhance its positive and reduce its negative impacts. ${ }^{5}$ 
Apesar de ser um fato do cenário internacional, verifica-se, atualmente, que não há um instrumento internacional amplo o qual regule a conduta dos Estados a respeito de todas as variáveis existentes na migração. O que há são normas internacionais que, ao regularem questões como segurança, nacionalidade, apatridia, liberdade de circulação de pessoas, unificação familiar, direitos humanos, saúde, tráfico de pessoas, refúgio, asilo, tocam na temática das migrações; ou, ainda, normas de proteção geral aos seres humanos que se aplicam também às pessoas em movimento.

Por outro lado, algumas situações de migrantes, sobretudo os refugiados e, mais recentemente, os deslocados internos, contam com sistemas de proteção internacional desenvolvidos ou em desenvolvimento e, mais do que isso, em função de sua condição diferenciada daquela dos demais migrantes, contam com a solidariedade, e até mesmo a simpatia, internacional.

O resultado é, muitas vezes, a ausência ou insuficiência de normas para solucionar as possíveis incoerências entre as normas de diversos campos, velando-se pela primazia dos direitos humanos no contexto das migrações. Além disso, essa ausência ou insuficiência normativa reflete na lacuna de mecanismos domésticos de proteção específicos, ou mecanismos domésticos que simplesmente permitam alcançar uma situação de regularidade dos imigrantes.

Em face disso, verifica-se a tendência de se buscar enquadrar todas as situações de migrantes nos poucos institutos legais internacionais específicos existentes, o que, por um lado, gera falta de utilização criteriosa das distinções entre os migrantes e, por outro lado, impede o desenvolvimento de novas formas de proteção, ao mesmo tempo que minimiza a efetividade das poucas normas existentes.

Exemplo disso é o fato de que inúmeros migrantes que deixaram seu país de origem ou de residência habitual por questões outras que o bem-fundado temor de perseguição, ou seja, que não são considerados como refugiados pelos critérios legais internacionais, busquem a proteção do refúgio, por ser este instituto um dos mais apurados na complexidade do tema da imigração.

Soma-se a este recurso indiscriminado à proteção do refúgio o fato de que, desde o atentado de 11 de setembro de 2001, vivencia-se uma tensão crescente entre normas antiterroristas e políticas migratórias, espelhadas em normas internas, com graves violações à proteção dos direitos humanos. Essa situação se agrava com a crise econômica, a xenofobia, o combate a crimes transnacionais, que acabam por minar a proteção de grupos vulneráveis de migrantes, tais como os trabalhadores migrantes, as mulheres e as crianças vítimas de tráfico, as pessoas apátridas, as pessoas deslocadas internamente e os refugiados.

Considerando os aspectos acima mencionados, verifica-se que uma tendência natural na busca de ampliação de proteção é tentar estabelecer um novo ramo do direito internacional, específico das migrações e fortemente fundado nos avanços conseguidos em prol da proteção dos refugiados. Contudo, este artigo pretende 
demonstrar que a proteção do refúgio, mesmo que alargada em resultado de instrumentos como a Convenção da antiga Unidade Africana $(1969)^{6}$ e a Declaração de Cartagena (1984), ${ }^{7}$ não deve ser utilizada para as diversas situações migratórias, sob pena de até mesmo enfraquecer o instituto e minimizar a proteção aos refugiados e aos migrantes em geral.

\section{BREVES CONSIDERAÇÕES HISTÓRICAS A RESPEITO DO APARECIMENTO DA NORMATIVA INTERNACIONAL DE PROTEÇÃO DAS PESSOAS EM MOVIMENTO}

Até o século XIX, muitos países não adotavam nenhum tipo de diferença em relação aos direitos dos nacionais e dos estrangeiros, e a livre circulação entre os países era permitida. Não obstante, há exemplos de perseguições, penas de exílio, crises de fome que forçaram pessoas a se deslocarem, assim como há exemplos da promoção da migração para colonizar terras conquistadas, no contexto do colonialismo e do imperialismo.

A Primeira Guerra Mundial trouxe mudanças quanto a isso, com restrições à liberdade de residência e diferenças entre os direitos de nacionais e de estrangeiros. Também teve início nesse contexto a formação do direito internacional dos refugiados, com os desenvolvimentos na Liga das Nações (FISCHEL DE ANDRADE, 1996). A Segunda Guerra Mundial, por sua vez, gerou um enorme fluxo de pessoas deslocadas e apátridas, as quais ficaram sem condições de retornar a seu local de origem, tendo sido consideradas como refugiados.

Diante do desafio, a sociedade internacional iniciou um processo de institucionalização, a fim de conferir proteção a estas pessoas - os refugiados e apátridas por meio do estabelecimento do Alto Comissariado das Nações Unidas para Refugiados (ACNUR) e da adoção de tratados, tais como a Convenção de 1951 e o Protocolo de 1967 sobre o status de refugiados, ${ }^{8}$ e as convenções de 1954 e 1961 sobre a apatridia. ${ }^{9}$

A Declaração Universal de Direitos Humanos (1948), ${ }^{10}$ documento matriz do sistema internacional universal de proteção da pessoa humana, estabeleceu em seu artigo 14 o direito de toda pessoa vítima de perseguição de procurar e de gozar asilo em outros países. Tal documento estabeleceu de maneira mais geral, no artigo 13, que todo homem tem direito à liberdade de locomoção e residência dentro das fronteiras de cada Estado, assim como direito de deixar qualquer país, inclusive o próprio, e a este regressar.

Paralelamente, desenvolveu-se a internacionalização dos direitos humanos, com a formação do sistema onusiano de direitos humanos e de sistemas regionais, tais como os sistemas interamericano, africano e europeu. No que diz respeito à migração em âmbito interamericano, a Declaração Americana dos Direitos e Deveres do Homem (1948) ${ }^{11}$ determina, no artigo $8^{\circ}$, que toda pessoa tem o direito de fixar sua 
residência dentro do território do Estado do qual é nacional, de transitar por ele livremente e de não deixá-lo, a menos que seja por sua própria vontade.

O Pacto Internacional sobre Direitos Civis e Políticos (1966) ${ }^{12}$ estabeleceu, no artigo 12, que: (1) todo indivíduo que se encontre legalmente no território de um Estado terá o direito de circular livremente por ele e de livremente estabelecer sua residência dentro dele; (2) todo individuo terá o direito de sair livremente de qualquer país, inclusive do seu próprio; (3) os direitos mencionados não poderão ser objeto de restrições, salvo quando estas se encontrarem estabelecidas em lei e forem necessárias para proteger a segurança nacional, a ordem, a saúde e a moral pública, ou os direitos e as liberdades dos outros, e forem compatíveis com os demais direitos reconhecidos no próprio Pacto; (4) ninguém poderá ser arbitrariamente privado do direito de entrar em seu próprio país.

Verifica-se, assim, que os instrumentos internacionais consagram, no que tange à migração, a liberdade de circulação, que somente pode ser restringida em face de devido processo legal, e o direito de asilo.

De modo genérico, os instrumentos de direitos humanos estabeleceram, ainda, a ideia da universalidade dos direitos humanos, pautada no princípio da não discriminação. Assim, nacionais e estrangeiros devem ter os mesmos direitos.

Todavia, percebe-se que a situação irregular submete muitos migrantes a uma situação a qual não os permite realizar seus direitos civis, políticos, sociais, econômicos e culturais, por temerem ser localizados pelas autoridades e estarem sujeitos à consequente aplicação das medidas de efetivação de seu retorno ao país de origem.

Não obstante as medidas de restrição impostas pelos Estados à migração, esta ocorre e acaba por gerar a situação dos migrantes irregulares ou não documentados. ${ }^{13}$ Assim, como direitos trabalhistas derivam de uma relação de trabalho, foram adotados tratados no âmbito da Organização Internacional do Trabalho (OIT) para versar sobre a situação dos trabalhadores migrantes, e, em 1990, adotou-se no marco do sistema onusiano de direitos humanos a Convenção sobre a Proteção dos Direitos de Todos os Trabalhadores Migrantes e suas Famílias. ${ }^{14}$

Esse último documento, em vigor desde 2003, é bastante abrangente e garante direitos aos trabalhadores migrantes que estejam regulares ou não no país de acolhida. Contudo, a adesão internacional a ele é bastante reduzida, contando com apenas quarenta Estados-partes. ${ }^{15,16}$

Nacionalmente, os países podem adotar normas internas a respeito dos direitos dos migrantes (estrangeiros), devendo, contudo, respeitar as obrigações assumidas internacionalmente e os padrões mínimos internacionais. Como a proteção aos refugiados é, há muito, uma preocupação e uma obrigação internacional, ${ }^{17}$ a maior parte dos Estados cria normas para proteger essa categoria de migrantes, o mesmo não ocorrendo com as demais. Além disso, nota-se que, em razão do contexto de crise econômica e das preocupações com a segurança nacional, os Estados têm adotado 
restrições à migração. A combinação desses fatores faz que, como mencionado acima, algumas pessoas, consideradas migrantes econômicos, busquem o refúgio como forma de obter a regularidade de sua entrada e permanência no país de destino. Além disso, pela ausência de procedimentos em âmbito nacional para conferir proteção a outras pessoas que dela necessitam, mas que não se enquadram como refugiados, tais pessoas também acabam por recorrer à proteção do refúgio.

Esse uso incorreto do instituto do refúgio ocorre também no âmbito internacional, em que se discute a utilização da proteção conferida pelo refúgio em casos, por exemplo, de deslocamento internacional decorrente de desastres ambientais, indicando que o direito internacional não criou formas específicas de proteção para novos casos de migração que demandam a proteção internacional.

Verifica-se, desta feita, que não há uma proteção internacional sistematizada às pessoas em movimento, o que leva à utilização inadequada dos poucos mecanismos existentes e, na prática, à vulnerabilidade dessas pessoas. Em face disso, e objetivando contribuir para a correção dessa falha, é relevante apresentar as distinções entre as situações de migrantes, também para que seja possível avaliar quais as formas mais adequadas de se garantir, ao menos, que os direitos mais fundamentais dessas pessoas sejam respeitados. É o que se passa a fazer a seguir.

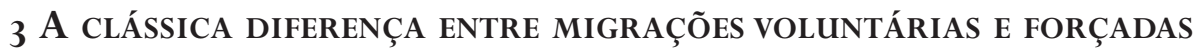

Os estudos a respeito de população, demografia e movimento de pessoas normalmente incluem o movimento de migrantes econômicos, refugiados e pessoas deslocadas no amplo conceito de migração, sendo esta analisada como um processo. Todavia, tal inclusão não tem sido aplicada, na prática, ao termo migrante, que não é entendido como um termo genérico, abrangendo várias categorias, tais como os refugiados, os deslocados e os migrantes econômicos. Um migrante é, em geral, considerado como um migrante econômico ou um trabalhador migrante e se diferencia de um refugiado ou outras pessoas que foram forçadas a se deslocar por causa da intervenção de um fator externo à sua vontade.

A Carta Constitutiva da Organização Internacional para Migrações, ${ }^{18}$ por exemplo, refere-se em momentos separados aos (1) migrantes e aos (2) refugiados, às pessoas deslocadas e outros indivíduos que necessitam de serviços internacionais de migração, ${ }^{19}$ conforme segue:

\section{Article 1}

The purposes and functions of the Organization shall be:

to make arrangements for the organized transfer of migrants, for whom existing facilities are inadequate or who would not otherwise be able to move without special assistance, to countries offering opportunities for orderly migration; 
to concern itself with the organized transfer of refugees, displaced persons and other individuals in need of international migration services for whom arrangements may be made between the Organization and the States concerned, including those States undertaking to receive them $[\ldots]$

Por um lado, essa distinção é relevante, uma vez que permite entender que a natureza e o escopo da proteção a ser garantida a um refugiado, por exemplo, sejam diferentes daqueles conferidos a um migrante trabalhador, o qual pode continuar a contar com a proteção do Estado do qual é nacional, em face do caráter complementar da proteção internacional. Mas, por outro lado, ela deveria partir da ótica das migrações em geral, e não dos migrantes, pois na realidade (1) tanto os migrantes forçados quanto os migrantes voluntários são migrantes e (2) a distinção a partir da ótica dos migrantes pode levar a processos de discriminação ou de categorização de pessoas as quais, em verdade, compartilham a mesma qualidade de dignidade inerente.

Assim, sendo a distinção entre as migrações forçadas e as migrações voluntárias relevante para o sistema atual de proteção das pessoas em movimento, uma vez que a proteção que será concedida às pessoas em cada uma dessas situações é distinta, passa-se a apontar as principais peculiaridades de cada situação. ${ }^{20}$

As migrações podem ser, desta feita, classificadas em migrações forçadas ou migrações voluntárias. ${ }^{21}$ As voluntárias abrangem todos os casos em que a decisão de migrar é tomada livremente pelo indivíduo, por razões de conveniência pessoal e sem a intervenção de um fator externo. Aplicam-se, portanto, a pessoas, e membros de sua família, que se mudam para outro país em busca de melhores condições sociais e materiais de vida para si e seus familiares. Essas pessoas podem ter um status de migração regular ou irregular, em função de sua entrada e permanência no país de residência, tenham ou não sido observados os requisitos legais previstos no país.

Já as migrações forçadas ocorrem quando o elemento volitivo do deslocamento é inexistente ou minimizado e abrangem uma vasta gama de situações.

A situação clássica de migração forçada é o refúgio que protege as pessoas as quais tiveram ou têm de deixar seu país de origem ou de residência habitual em razão de bem-fundado temor de perseguição em função de sua raça, religião, nacionalidade, opinião política ou de pertencimento a um grupo social, nos termos da Convenção de 1951 e do Protocolo de 1967; ou, no caso da América Latina, também por grave e generalizada violação de direitos humanos.

A Convenção de 1951 e o Protocolo de 1967 trazem os direitos dos refugiados e solicitantes de refúgio e os deveres dos Estados para com eles, bem como regulamentam a proteção de outras pessoas que estejam sob o mandato do Alto Comissariado das Nações Unidas para Refugiados, como os apátridas, retornados e reassentados. ${ }^{22}$

Além dos refugiados, também se enquadram nas migrações forçadas as pessoas deslocadas internamente, seja por questões de conflitos armados, desastres ambientais 
ou graves violações de direitos humanos. Essas pessoas continuam sob a proteção de seu Estado, o que faz que a proteção internacional seja peculiar.

Um terceiro grupo de pessoas em movimento sujeito a migrações forçadas é o dos deslocados ambientais, muitas vezes apresentados como refugiados ambientais. As mudanças ambientais, sobretudo as climáticas, têm provocado o deslocamento de milhões de pessoas, fenômeno que tende a se agravar. Essas pessoas, às vezes, tornam-se deslocadas internas e, outras vezes, cruzam fronteiras internacionais. Quanto a este último caso, tem-se debatido se elas poderiam se enquadrar no sistema de proteção aos refugiados, o que não parece adequado, por faltar a característica básica desse sistema, qual seja a perseguição.

As migrações forçadas englobam também pessoas as quais tiveram de se deslocar em função de situações relativas a seus direitos econômicos, sociais ou culturais. Nesses casos, pode existir uma falta de efetivação grave de tais direitos ou a realização de obras e atividades que visem mediatamente a acelerar o desenvolvimento, mas que imediatamente causam deslocamentos.

Há ainda indivíduos os quais necessitam de serviços de migração, como é o caso de pessoas que enfrentam violações de direitos humanos em seu próprio país e ainda se encontram neste país (prisioneiros políticos, por exemplo), em geral no contexto de uma situação de tensão política interna ou conflito armado não internacional, ou qualquer outra espécie atípica de migração em que o indivíduo não se caracterize como migrante, refugiado ou pessoa deslocada.

Conclui-se, portanto, que quanto a este amplo grupo é preciso diferenciar entre aqueles que podem contar com a proteção do seu país de origem ou residência e aqueles que não podem recorrer a esta proteção, a fim de se verificarem formas de aprimorar a proteção internacional de todos.

\section{A Proteção internacional No ÂMbito dA migração}

\section{I OS MIGRANTES ECONÔMICOS E A SUA PROTEÇÃO INTERNACIONAL}

Não há uma definição jurídica da palavra migrante. Em geral, na legislação doméstica dos Estados, referência é feita somente a estrangeiros e o seu direito de entrar, permanecer e trabalhar. Em âmbito internacional, existem definições variadas de trabalhadores migrantes, sendo relevante mencionar aquela adotada pela Convenção sobre a Proteção dos Direitos de Todos os Trabalhadores Migrantes e suas Famílias, de 1990, instrumento componente do sistema onusiano de direitos humanos.

De acordo com ela, o trabalhador migrante é aquela pessoa que desempenha uma atividade remunerada em um Estado do qual ele não é um nacional. A definição inclui os migrantes não documentados ou migrantes em situação irregular (por causa de sua entrada, estada ou trabalho), trabalhadores que atuam nas fronteiras, trabalhadores 
sazonais, trabalhadores de instalações offshore, trabalhadores itinerantes e trabalhadores autônomos; e exclui os refugiados e apátridas, estudantes e trainees. ${ }^{23}$

Verifica-se, assim, que a proteção internacional específica é bastante precária em relação aos migrantes, o que deve ser revisto. Em face do atual cenário internacional, a adoção e a efetivação de novos mecanismos de proteção não serão viáveis. Assim, é indispensável que, por um lado, os Estados de origem dessas pessoas atuem por meio da proteção diplomática, a fim de protegê-los quando estiverem no exterior, e que, por outro lado, os instrumentos gerais de direitos humanos sejam aplicados, uma vez que são de titularidade universal e devem ser respeitados em quaisquer situações.

Dessa forma, ter-se-ia assegurado um mínimo de proteção, enquanto se tenta coadunar os interesses dos Estados com as necessidades dos migrantes e elaborar documentos mais específicos de proteção.

\subsection{OS REFUGIADOS, AS PESSOAS EM CONDIÇÃO ANÁLOGA À DOS REFUGIADOS E A SUA PROTEÇÃO INTERNACIONAL}

Como visto, os refugiados são os migrantes forçados que contam com o sistema mais completo de proteção. Tal sistema traz uma definição clara das pessoas na condição de refugiadas e dos direitos e deveres que decorrem de tal situação.

Ademais de contarem com o sistema universal previsto na Convenção de 1951 e no Protocolo de 1967, os refugiados contam com proteção em âmbito regional, em que há a extensão da proteção a outros casos, em âmbito africano e americano.

A Convenção da antiga Organização da Unidade Africana, atual União Africana, que rege os aspectos específicos dos problemas dos refugiados na África, foi adotada em 1969, sendo um instrumento regional mandatório. Ela constitui o único tratado regional a respeito de refugiados legalmente vinculante, tendo sido adotada no contexto dos conflitos que acompanharam o fim da era colonial na África e levaram a uma sucessão de movimentações de pessoas em larga escala. Esse instrumento inclui entre os refugiados qualquer pessoa que, em razão de uma agressão, ocupação externa, dominação estrangeira, ou de acontecimento que perturbe gravemente a ordem pública, em uma parte ou na totalidade do seu país de origem ou do país de que tem nacionalidade, seja obrigada a deixar seu país. Deste modo, não se exige dessas pessoas o receio fundado de perseguição.

Em 1984, um colóquio de representantes de governos e juristas adotou a Declaração de Cartagena, instrumento regional não mandatório. A Declaração recomendou que na definição de refugiado utilizada na América Latina considere-se também como tal, além das previsões universais, a pessoa que tenha fugido do seu país porque sua vida, sua segurança ou sua liberdade tenham sido ameaçadas pela violência generalizada, pela agressão estrangeira, pelos conflitos internos, pela violação maciça dos direitos humanos, ou outras circunstâncias que tenham perturbado gravemente a ordem pública. 
Em âmbito doméstico, cada Estado é livre para legislar internamente, ampliando a proteção conferida pelo refúgio a outras hipóteses não previstas nos instrumentos internacionais. Todavia, o direito internacional atualmente confere proteção em conformidade com o previsto na Convenção de 1951 e no Protocolo de 1967.

A Convenção de 1951 e seu Protocolo fornecem aos Estados-partes a base jurídica da proteção, destacando-se o princípio do non-refoulement, ou seja, da impossibilidade de devolução do solicitante de refúgio (enquanto pendente a sua solicitação) e do refugiado a um país em que haja risco de perseguição. Por sua vez, o ACNUR tem o mandato, previsto em seu estatuto, adotado pela Assembleia Geral da Organização das Nações Unidas (ONU) em 1950, de assegurar a proteção internacional aos refugiados e procurar soluções duradouras para seus problemas. O mandato do ACNUR vem sendo alargado, desde então, por meio de resoluções da Assembleia Geral das Nações Unidas, o que inseriu sob a responsabilidade do ACNUR categorias de pessoas não abrangidas pela Convenção de 1951 e seu Protocolo: pessoas que fogem de um conflito ou de acontecimentos que perturbem gravemente a ordem pública (refugiados ao abrigo da Convenção Africana e da Declaração de Cartagena); refugiados sob mandato; retornados; apátridas; e, em algumas situações, as pessoas deslocadas internamente.

Todavia, a previsão de proteção pelo mandato do ACNUR não torna tais pessoas refugiados. Além disso, deve-se ressaltar que o estatuto e as resoluções da Assembleia Geral da ONU a respeito do mandato do ACNUR definem as responsabilidades e funções deste órgão, sendo ele, portanto, diferente de um tratado que vincula os Estados signatários, especificando os direitos e as obrigações das pessoas reconhecidas como refugiados.

Cumpre lembrar que os palestinos constituem um caso especial perante o direito internacional. Em 1948, foi instituído o Organismo da ONU das Obras Públicas e Socorro aos Refugiados da Palestina no Próximo Oriente (UNRWA, em sua abreviatura em inglês), ${ }^{24}$ para prestar assistência aos palestinos que foram deslocados por ocasião da criação do Estado de Israel. O UNRWA define como refugiados palestinos todas as pessoas - e seus descendentes - que residiam na Palestina dois anos antes das hostilidades de 1948 e que perderam as suas casas e os meios de subsistência em consequência do conflito. Ao UNRWA não foi atribuído um mandato para proteger os refugiados palestinos, sendo esta responsabilidade deixada aos países no qual eles buscaram refúgio.

Os apátridas, por sua vez, são pessoas que não são consideradas por nenhum Estado, nos termos de seu ordenamento jurídico, como seu nacional. O apátrida pode ser um refugiado e, nesta hipótese, estaria sob a proteção dos instrumentos internacionais e das legislações nacionais a respeito do refúgio, mas não necessariamente se enquadra nos critérios para o reconhecimento do status de refugiado.

A apatridia tem estreita relação com o deslocamento, do que decorre o envolvimento do ACNUR com o tema. O deslocamento pode ser a causa da apatridia 
(deslocamento seguido de redefinição de fronteiras territoriais), pode ser uma consequência da apatridia (quando a pessoa apátrida é forçada a deixar o local de residência), pode ser um obstáculo à solução duradoura dos refugiados (quando um Estado se recusa a permitir a entrada de repatriados, quando não se pode provar a nacionalidade anterior pela ausência de documentos ou mesmo de registro de nascimento).

Em âmbito internacional, a Convenção sobre o Estatuto dos Apátridas, de 1954, contribui para regularizar e melhorar o estatuto dos apátridas e para assegurar que eles gozem, sem discriminação, dos direitos humanos, ou seja, a Convenção visa a garantir direitos humanos aos apátridas. Por sua vez, a Convenção sobre a Redução da Apatridia, de 1961, define formas mediante as quais pessoas apátridas podem adquirir ou conservar uma nacionalidade, por meio de laços a um Estado por nascimento ou ascendência, e visa à resolução de situações que provocam a apatridia. Contudo, nenhuma das duas convenções estabelece processo de solicitação de um status de permanência por razões de apatridia.

Aqui, é interessante mencionar também os asilados. Isso porque, sobretudo na América Latina, coexistem os institutos do refúgio e do asilo, ambos espécies do direito de asilo consagrado internacionalmente.

O asilo tem origens na Antiguidade Clássica e, hoje em dia, é um ato discricionário do Estado visando a proteger pessoas que sofram perseguição, geralmente políticas. Ele pode ser concedido no território efetivo do Estado (asilo territorial) ou em embaixadas, consulados ou legações (asilo diplomático).

Verifica-se, assim, que o asilo se distingue do refúgio, pois este não é discricionário, tem como base o fundado temor de perseguição e pode ser baseado em outras razões que não a opinião política.

O quadro 1 apresenta isso de forma esquemática. ${ }^{25}$

\section{Quadro 1 - Semelhanças e diferenças entre asilo e refúgio}

ASILO

REFÚGIO

\begin{tabular}{|c|c|c|}
\hline \multirow[t]{5}{*}{ SEMELHANÇAS } & \multicolumn{2}{|c|}{$\begin{array}{l}\text { OBJETIVOS: AMBOS VISAM À PROTECCÃO DE INDIVÍDUOS POR OUTRO ESTADO QUE NÃO } \\
\text { O DE ORIGEM E/OU RESIDÊNCIA HABITUAL DESSES. }\end{array}$} \\
\hline & \multicolumn{2}{|c|}{$\begin{array}{l}\text { FUNDAMENTACCÃO: AMBOS SE FUNDAM NA SOLIDARIEDADE E NA COOPERAÇÃO } \\
\text { INTERNACIONAIS. }\end{array}$} \\
\hline & \multicolumn{2}{|c|}{$\begin{array}{l}\text { FUNDAMENTACCÃO LEGAL: AMBOS SE FUNDAM NO RESPEITO AOS DIREITOS HUMANOS } \\
\text { E, CONSEQUENTEMENTE, AMBOS PODEM SER ENTENDIDOS COMO ABARCADOS PELO } \\
\text { DIREITO INTERNACIONAL DOS DIREITOS HUMANOS. }\end{array}$} \\
\hline & \multicolumn{2}{|c|}{ CARÁTER: AMBOS TÊM CARÁTER HUMANITÁRIO. } \\
\hline & \multicolumn{2}{|c|}{ PROTEÇÃO ASSEGURADA: A SAÍDA COMPULSÓRIA DESTAS PESSOAS FICA LIMITADA. } \\
\hline \multirow[t]{2}{*}{ DIFERENÇAS } & DATA DA ANTIGUIDADE. & É POSITIVADO TÃO SOMENTE NO SÉCULO XX. \\
\hline & $\begin{array}{l}\text { ATUALMENTE, É PRATICADO } \\
\text { PRINCIPALMENTE NA AMÉRICA LATINA. }\end{array}$ & TEM ABRANGÊNCIA UNIVERSAL. \\
\hline
\end{tabular}


TEMA DE TRATADOS REGIONAIS DESDE O SÉCULO XIX.

HIPÓTESES DISCRICIONÁRIAS DE CONCESSÃO.

LIMITADO A QUESTÕES POLÍTICAS.

BASEIA-SE NA PERSEGUIÇÃO EM SI

NÃO EXISTE UM ÓRGÃO INTERNACIONAL ENCARREGADO DE FISCALIZAR A PRÁTICA DO ASILO.

NÃO EXIGE QUE O INDIVÍDUO ESTEJA FORA DE SEU ESTADO DE ORIGEM E/OU NACIONALIDADE (NA MODALIDADE DO ASILO DIPLOMÁTICO).

NÃO HÁ CLÁUSULAS DE EXCLUSÃO.

NÃO HÁ CLÁUSULAS DE CESSAC̣̃̃O

\section{DECISÃO DE CONCESSÃO DE ASILO} É CONSTITUTIVA.

DA CONCESSÃO NÃO DECORREM OBRIGACÕES INTERNACIONAIS AO ESTADO DE ACOĹHIDA.

NÃO DECORREM POLÍTICAS DE INTEGRAÇÃO LOCAL.
TEM COMO BASE TRATADOS UNIVERSAIS, SENDO SOMENTE A PARTIR DA DÉCADA DE 1960 QUE ELE PASSA A SER TEMA DE TRATADOS REGIONAIS.

HIPÓTESES CLARAS DE RECONHECIMENTO DO STATUS DE REFUGIADO.

CINCO MOTIVOS: OPINIÃO POLÍTICA, RAÇA, RELIGIÃO, NACIONALIDADE E PERTENCIMENTO A GRUPO SOCIAL).

O ELEMENTO ESSENCIAL DE SUA CARACTERIZACÃO É O BEM FUNDANDO TEMOR DE PERSEGUIÇÃO, OU SEJA, A PERSEGUICÃO NÃO PRECISA TER SIDO MATERIALIZÁDA

EXISTE UM ÓRGÃO INTERNACIONAL ENCARREGADO DE FISCALIZAR A PRÁTICA DO REFÚGIO.

EXIGE QUE O INDIVÍDUO ESTEJA FORA DE SEU ESTADO DE ORIGEM E/OU NACIONALIDADE.

TEM LIMITAC̄ÕES QUANTO ÀS PESSOAS QUE PODEM GOZAR DELE ICLÁUSULAS DE EXCLUSÃO), PARA QUE SEJA COERENTE COM OS PRINCÍPIOS E PROPÓSITOS DA ONU, UMA VEZ QUE É UM ÓRGÃO DESSA ORGANIZACTÃO QUE FISCALIZA A SUA APLICAÇÃO.

A PROTEĊÃO CONCEDIDA PELO REFÚGIO TEM PREVISÕES PARA DEIXAR DE EXISTIR (CLÁUSULAS DE CESSAÇÃO).

RECONHECIMENTO DO STATUS DE REFUGIADO É DECLARATÓRIO.

DO RECONHECIMENTO DO STATUS DE REFUGIADO DECORREM OBRIGAC̣ÕES INTERNACIONAIS AO ESTADO DE ACOLHIDA.

DEVEM DECORRER POLÍTICAS DE INTEGRAÇÃO LOCAL DOS REFUGIADOS.

Verifica-se, assim, que, no âmbito internacional, os refugiados e as pessoas em condições análogas (com exceção dos asilados) à dos refugiados contam com proteção, existindo documentos e órgãos internacionais específicos e encarregados de assegurar o respeito aos direitos humanos destas pessoas em movimento. Como a proteção se efetiva nos territórios de Estados, há a possibilidade de aprimoramento de situações específicas, mas a proteção internacional assegurada é razoavelmente desenvolvida.

\subsection{OS DESLOCAdOS INTERNOS E A SUA PROTEÇÃO INTERNACIONAL}

No caso dos deslocados internos, as Linhas de Orientação da ONU sobre Deslocamento Interno ${ }^{26}$ definiram como pessoas deslocadas internamente aquelas 
pessoas ou grupos de população que foram forçados a fugir e abandonar as suas casas ou os seus locais de residência habitual, em razão de conflitos armados, situações de violência generalizada, violações de direitos humanos e calamidades naturais ou provocadas pelo homem, ou a fim de evitar os seus efeitos, e que não atravessaram qualquer fronteira internacionalmente reconhecida de um Estado.

Os deslocados internos, uma vez que permanecem no seu próprio país de origem, não podem ser considerados refugiados - nem estavam inicialmente sob o abrigo do mandato do ACNUR. Não há nenhum tratado internacional ou agência especificamente voltada à proteção dessas pessoas. Atualmente, a proteção se faz pela abordagem conjunta (cluster approach) das agências que atuam em diversas áreas (como o UNICEF e a Organização Mundial da Saúde) e também pelo ACNUR, a quem foi atribuída a responsabilidade de proteção em relação aos deslocados internos.

Como os deslocados internos seguem dentro de seus Estados, a proteção internacional somente ocorre mediante a observação de alguns critérios: (1) existência de uma solicitação ou autorização da Assembleia Geral ou de outro órgão superior e competente da ONU; (2) consentimento do Estado interessado e, quando aplicável, de outras entidades envolvidas no conflito; (3) acesso à população afetada; (4) condições de segurança adequadas para o pessoal do ACNUR e seus parceiros; (5) linhas claras de obrigações e responsabilidades; (6) capacidade e recursos adequados.

A atuação das agências e dos órgãos internacionais se faz em conformidade com as mencionadas Linhas de Orientação da ONU, instrumento não mandatório, inspirado no direito internacional dos direitos humanos, no direito humanitário e no direito internacional dos refugiados. Tal instrumento consolidou os mais importantes princípios de proteção internacional aplicados às pessoas deslocadas internamente e teve como principal objetivo orientar os Estados, os atores não estatais, as organizações intergovernamentais e não governamentais a respeito do deslocamento interno. Além disso, cumpre ressaltar que, nos casos em que o deslocamento interno decorra de uma situação de conflito interno, o Comitê Internacional da Cruz Vermelha (CICV) entende que sua atuação é demandada, em face de seu mandato.

Nota-se que o sistema de proteção aos deslocados internos tem evoluído a partir da prática. Atualmente, conta, ao menos, com princípios reitores, que consideram a especificidade da situação dos deslocados e tentam responder às necessidades básicas dessa população, podendo ser apontados como o início de uma proteção internacional a esses migrantes.

\subsection{OS DESLOCADOS POR QUESTÕES AMBIENTAIS E A SUA PROTEÇÃO INTERNACIONAL}

A proteção a ser conferida aos deslocados por razões ambientais tem sido objeto de debate internacional (LOPEZ, 2007). O direito internacional do meio ambiente desenvolveu-se com normas preventivas e punitivas no que diz respeito à degradação 
ambiental, e o direito internacional dos direitos humanos e o direito internacional humanitário tratam dos efeitos adversos da degradação ambiental nos seres humanos.

A migração resultante de um meio ambiente temporariamente ou permanente degradado é um fato incontestável; todavia, o direito internacional não tem disposições concernentes à correlação entre a degradação ambiental e a migração humana. Os poucos estudos sobre o tema focam normalmente em como a chegada de grandes levas de migrantes pode afetar o meio-ambiente, como no caso da construção de campos de refugiados, e não em como a degradação ambiental pode gerar deslocamentos.

O evento-marco no desenvolvimento de estudos a respeito da migração causada por razões ambientais foi um relatório do Programa das Nações Unidas para o Meio Ambiente (PNUMA), de 1985 (EL-HINNAWI, 1985). Do ponto de vista do direito internacional, a expressão refugiados ambientais não é correta, pois a definição dada pelo direito internacional à palavra refugiado abrange critérios específicos que fazem que uma pessoa possa receber a proteção do refúgio. A Convenção de 1951 não foi redigida para abranger as pessoas deslocadas por razões ambientais, e isso não é possível ainda que se interprete o instrumento atualizando-o ao contexto atual. A principal questão ressaltada pela doutrina (KOZOLL, 2004) é que na maioria das situações não se vislumbra perseguição ou ação concertada de uma entidade identificável ou mesmo do Estado.

Diferentemente das vítimas de perseguição, as pessoas que se deslocam em razão de um desastre ambiental podem, em geral, valer-se da ajuda e do suporte do próprio governo, mesmo que tal suporte seja limitado. Isso não se confunde com a situação em que o agente perseguidor utiliza a degradação ambiental como meio de perseguição. Neste caso, a razão da perseguição pode ser uma das previstas na Convenção de 1951, e a forma de perseguição é o dano ambiental; assim, trata-se de um refugiado. Nesse sentido, deve-se estabelecer o fundado temor de perseguição.

Contudo, há a possibilidade de, em âmbito regional e nacional, conferir-se proteção por intermédio do refúgio, na medida em que organizações internacionais ou Estados estenderam a proteção conferida pelo instituto a pessoas fugindo de acontecimentos que perturbem gravemente a ordem pública. Essa previsão poderia ser aplicada às pessoas que deixam seu pais em razão de desastres ambientais (MCCUE, 1993).

Verifica-se, assim, a necessidade de se desenvolver um sistema próprio para os deslocados ambientais, uma vez que eles não se enquadram nas definições de refugiados, e a reforma destas parece improvável e indesejável, pois, em um cenário restritivo às migrações, as reformas podem pôr em risco a proteção já existente, minimizando as garantias aos refugiados.

\subsection{OS DESLOCADOS POR QUESTÕES DE DIREITOS ECONÔMICOS, SOCIAIS E CULTURAIS E DE DESENVOLVIMENTO, E A SUA PROTEÇÃO INTERNACIONAL}

Nos dias atuais, a diferença entre o status de refugiado e a situação de migrante econômico não é fácil quando se está em jogo a violação a direitos econômicos, sociais 
e culturais. ${ }^{27}$ Historicamente, há que se recordar que, em função dos conflitos ideológicos que marcaram o período da Guerra Fria e se refletiram na doutrina e na normativa internacional de direitos humanos, os direitos econômicos, sociais e culturais foram por muito tempo considerados por alguns autores e Estados como aspirações, e não direitos humanos. Todavia, cumpre buscar pelos elementos definidores do status de refugiado e verificar se uma pessoa deslocada por questões de direitos econômicos, sociais e culturais pode recorrer ao refúgio, ou deve ser concedido a ela outro tipo de proteção.

Ao se considerar a necessidade da existência de um fundado temor de perseguição para a caracterização do status de refugiado, a motivação decorrente de violação de direitos econômicos, sociais e culturais fica mais complicada, visto que a violação desses direitos ocorre mais pela negligência do que por meio de um ato formal ou de ações concertadas de um agente perseguidor. Além disso, quase sempre é difícil separar a situação de um indivíduo das condições gerais no seu país de origem ou residência habitual. Contudo, há casos em que há uma interseção entre o fato de se pertencer a um grupo social e o acesso à educação e à saúde. Mas, nesses casos, a perseguição pode ser caracterizada por pertencimento a grupo social.

No mesmo sentido, pode-se fazer uma relação com situações de indivíduos e tratados de direitos humanos que definem certos grupos, tais como a Convenção sobre a Eliminação de Todas as Formas de Discriminação contra as Mulheres, a Convenção sobre Direitos das Crianças, a Convenção a respeito dos Trabalhadores Migrantes e suas Famílias, já mencionada, e a Convenção sobre Direitos das Pessoas com Deficiência. Há, além desses, outros grupos definidos por características comuns as quais levam à discriminação, como pessoas infectadas pelo vírus da AIDS, ou com outras doenças.

Há razões para considerar a privação de direitos econômicos e sociais em certos casos; por exemplo, a privação ao direito ao trabalho, à educação, à saúde como fundamento para o reconhecimento do status de refugiado.

O dilema dos direitos econômicos, sociais e culturais encontra-se no fato de que, se um Estado falha em prover tais direitos para toda a população por meio de políticas e programas, é difícil argumentar casos individuais, alegando que tais direitos não são realizados. O que se pode argumentar é que, em razão de suas opiniões políticas, sua etnia, ou de pertencimento a algum grupo social, esses indivíduos são privados por um agente - o Estado ou outra entidade com poder suficiente - de trabalhar, de receber educação ou tratamento de saúde. O ponto crucial é que o Estado, ou outro agente atua contra o indivíduo, e isso constitui uma perseguição.

Menos clara é a situação quando não há nenhuma ação por parte desse agente, mas sim negligência. Os Estados podem argumentar que os recursos não são suficientes para permitir a proteção de certos direitos, como, por exemplo, fornecer o tratamento para pessoas infectadas pelo HIV. 
Portanto, uma solicitação de refúgio em que há direitos econômicos, sociais e culturais sendo violados pode ser atendida se houver um caso de discriminação dirigida a um grupo; caso contrário, será difícil demonstrar o fundado temor necessário para a caracterização do refúgio.

Se a violação de direitos econômicos e sociais se tornar um fundamento por si só para o reconhecimento do status de refugiado, poderá haver um aumento considerável no movimento internacional de pessoas em busca de um padrão de vida adequado.

A análise que poderia ser feita é a seguinte: se o Estado de origem tentou e tem tentado melhorar a implementação dos direitos econômicos, sociais e culturais da sua população, sem discriminação, não haveria fundamentos para alegar perseguição. Entretanto, se o Estado falha nessa tarefa, discriminando parte da população na provisão dos serviços voltados à realização desses direitos, existe argumento fundado em discriminação a determinado grupo social, motivo este previsto originalmente na Convenção de 1951 e que atendeu, por exemplo, aos ciganos vitimados durante o regime nazista.

Contudo, ainda assim uma parte de indivíduos aos quais é negado o direito ao desenvolvimento, consoante a Declaração sobre Direito ao Desenvolvimento (1986), ${ }^{28}$ continua sem proteção internacional.

O direito ao desenvolvimento é objeto de inúmeros debates no âmbito internacional, sendo que no âmbito da ONU lhe foi atribuída a noção de síntese de todos os direitos humanos, baseada na interdependência e indivisibilidade dos direitos humanos (OLIVEIRA, 2004). Logo, quando se fala em violações graves e sistemáticas de direitos humanos, há que se indagar se a privação do direito ao desenvolvimento não poderia configurar uma situação merecedora de proteção internacional.

A situação de Estados em que se verifica ausência de instituições democráticas e níveis elevados de pobreza que alcançam a maioria da população pode resultar em algo insustentável para os indivíduos, apresentando índices altos de mortalidade infantil e materna, desnutrição e analfabetismo. Pode-se falar simplesmente: "Triste daquele que nasceu neste país!"; pode-se buscar por meio da cooperação internacional reverter o quadro de desenvolvimento do Estado - todavia, isso demanda longo prazo -; ou se pode tentar diferenciar mesmo, entre as situações de ausência de desenvolvimento, aquelas que resultam em pessoas as quais demandam proteção internacional, visto que o futuro certo com fome e doenças configura sim fator externo que compele o individuo à migração, mesmo não havendo uma perseguição configurada.

Nesses casos, há elementos para se argumentar a aplicação da proteção estendida nos termos da Convenção Africana de 1969 e da Declaração de Cartagena de 1984, que não demandam a existência da perseguição para a concessão da proteção do refúgio, mas somente a configuração de situações objetivas, entre as quais se destaca a vida ameaçada por violação maciça dos direitos humanos, ou ainda a relação com a ordem pública, em face de um Estado fraco e incapaz de prover o mínimo necessário para se viver. 
Por fim, em relação aos direitos econômicos, sociais e culturais e à efetivação do direito ao desenvolvimento, cumpre mencionar o deslocamento de pessoas em função de construção de obras as quais visam ao aprimoramento da infraestrutura do país, tais como a construção de hidrelétricas de barragens ou a realização de obras de desvio do leito dos rios. Nessas situações, ter-se-ia o deslocamento em função da efetivação de direitos econômicos, sociais e culturais, e não em função de sua ausência, mas, embora com fundamentos diferentes, ter-se-ia o mesmo resultado prático: a necessidade de as pessoas deixarem seus locais de residência.

Tal situação enseja um sistema de proteção distinto dos mencionados aqui, pois as pessoas deslocadas em razão dessas condições permanecem sob a responsabilidade de seus Estados, estando, assim, mais próximas da condição de deslocados internos e, consequentemente, submetidas ao sistema de proteção a estes, o qual se encontra em face de construção.

Verifica-se, assim, que tanto pela falta de efetivação quanto pela realização de obras a fim de garanti-los, há possibilidade de migrações em função de direitos econômicos, sociais e culturais, o que impõe mais uma séria de desafios à busca de proteção internacional nas migrações.

\section{CONCLUSÃo}

As realidades políticas, sociais, econômicas e ambientais estão gerando movimentações de pessoas envolvidas em situações cada vez mais complexas e sem previsão internacional de proteção, demandando a aplicação do direito internacional dos direitos humanos e dos princípios humanitários, e a criação, pelos Estados, de sistemas de proteção complementar (MCADAM, 2005).

A sociedade internacional deve se preocupar com o fato de que os critérios definidores do status de refugiado e as responsabilidades dos Estados vinculadas a este status perdem sua precisão pelo uso do instituto do refúgio para proteger pessoas não elencadas pelo Direito Internacional como passíveis de receber esta proteção específica (FELLER, 2006). Tal preocupação não deve, contudo, impedir ou prejudicar a proteção de outras pessoas em movimento, seja este fruto de migrações forçadas ou a migrações voluntárias.

Sendo a migração um dado do cenário internacional, o direito internacional deve buscar assegurar normas que coadunem os interesses dos Estados e as necessidades de proteção dos seres humanos e de todas as facetas e dimensões de sua dignidade.

Essa proteção não parece advir de um direito internacional de migrações, uma vez que as situações dos migrantes parecem muito diversas em suas causas e motivações, e os níveis de proteção existentes são bastante divergentes, o que poderia levar a injustiças caso se tratassem situações desiguais de forma similar. 
As bases da proteção já existem no direito internacional dos direitos humanos. Em vez de se propugnar pela criação teórica de um ramo autônomo do direito internacional, o foco deve ser a proteção prática dos migrantes, para, a partir da realidade e do desenvolvimento fático da proteção, começar a se pensar em construções teóricas. Nesse sentido, o recurso aos mecanismos convencionais e não convencionais do sistema internacional e dos sistemas regionais de direitos humanos nos casos em que os Estados violem as obrigações assumidas em tratados de direitos humanos, no contexto das migrações, pode contribuir para o respeito à dignidade dos migrantes.

: ARTIGO APROVADO (15/01/2010) : RECEBIDO EM 24/04/2009

\section{NOTAS}

1 Os autores defendem a ideia de um regime normativo unitário para a análise jurídica do movimento humano, compreendendo que as múltiplas respostas à imigração, embora diversas, podem ser reunidas. Este livro possui uma perspectiva diferente da publicação de 2003 Migração e Normas Jurídicas Internacionais, que defendia a ideia de que um regime coerente de normas internacionais a respeito da migração ainda não havia emergido. Tal publicação também reflete a denominação do Departamento de Assuntos Jurídicos e Direito Internacional da Migração no âmbito da Organização Internacional para Migração (OIM).

2 A Organização das Nações Unidas divulgou recentemente que, em função da nova crise econômica global, 10 milhões de pessoas podem se tornar migrantes. Informação obtida em: O Estado de São Paulo, 27 de dezembro de 2008, Caderno de Economia. Disponível em: <http://www.estadao.com.br/economia/not_eco299536,0.htm>.

3 Informação disponível em: <http://www.iom.int/jahia/Jahia/about-migration/facts-and-figures/globalestimates-and-trends $>$. Acesso em janeiro de 2009.

4 Informação disponível em: <http://www.iom.int/jahia/Jahia/lang/en/pid/241>. Acesso em janeiro de 2009.

5 Disponível em: <www.acnur.org/t3/portugues/documentos/?tx_danpdocumentdirs_pi2\%5Bpointer\%>. Acesso em janeiro de 2009.

6 Disponível em: <http://www.unhcr.org/basics/BASICS/45dc19084.pdf>. Acesso em janeiro de 2009.

7 Ver: <http://www.unhcr.org/protect/PROTECTION/3b66c2aa10.pdf>. Acesso em janeiro de 2009.

8 Ver: <http://www.unhcr.org/protect/PROTECTION/3bbb25729.pdf>; <http://www.unhcr.org/protect/ PROTECTION/3bbb286d8.pdf>. Acesso em janeiro de 2009.

9 Disponível em: <http://www.unhchr.ch/udhr/lang/eng.htm>. Acesso em janeiro 2009.

10 Disponível em: <https://www.cidh.oas.org/Basicos/Portugues/b.Declaracao_Americana.htm>. Acesso em janeiro de 2009. 
11 Disponível em: <http://www2.ohchr.org/english/law/ccpr.htm>. Acesso em janeiro de 2009.

12 Cumpre destacar que a doutrina mais moderna não utiliza a expressão migrantes ilegais, a fim de (1) não criminalizar uma conduta que geralmente é uma infração administrativa e (2) não estigmatizar os migrantes ao lhes imputar uma conduta ilegal.

13 Disponível em: <http://www2.ohchr.org/english/law/cmw.htm>. Acesso em janeiro de 2009. Houve também a adoção, em 2000, de um Protocolo contra o Tráfico de Migrantes por Terra, Mar e Ar, complementando a Convenção das Nações Unidas contra o Crime Organizado Transnacional; Tal documento ainda não está em vigor, mas pode ser visto em: <http://www2. ohchr.org/english/law/organizedcrime.htm>. Acesso em janeiro de 2009.

14 Há uma campanha da sociedade civil brasileira e de órgãos de proteção aos direitos humanos no sentido de que o Brasil ratifique tal convenção. A estimativa da OIM é de que existem 1,5 milhões de estrangeiros vivendo no Brasil e 3 milhões de brasileiros vivendo no exterior. Informações obtidas em: <http://www.iom.int/jahia/Jahia/pid/444>. Acesso em janeiro de 2009 .

15 Informações obtidas em: <http://www2.ohchr.org/english/bodies/ratification/13.htm>. Acesso em janeiro de 2009.

16 Atualmente, 147 Estados fazem parte da Convenção de 1951 ou do Protocolo de 1967. Informação obtida em: <http://www.unhcr.org/protect/PROTECTION/3b73b0d63.pdf>. Acesso em janeiro de 2009.

17 Disponível em: <http://www.iom.int/jahia/Jahia/about-iom/constitution/chapter-I-purposes-andfunctions $>$. Acesso em janeiro de 2009.

18 Para tanto, ver: PERRUCHOUD, Richard, Persons falling under the Mandate of the International Organization for Migration (IOM) and to Whom the Organization may Provide Migration Services.

19 Note-se que, ainda que se utilizem os termos migrantes forçados ou migrantes voluntários, isso se fará com base no espírito do exposto anteriormente, ou seja, para distinguir os fenômenos migratórios vivenciados por essas pessoas em movimento, e não como forma de categorizar seres humanos.

20 Sobre as classificações de migrações ver: JUBILUT, Liliana Lyra, Migrações e Desenvolvimento, em AMARAL JR., Alberto do (org.), Direito Internacional e Desenvolvimento (São Paulo: Manole, 2005, p. 123-54).

21 Ver: <http://www.unhcr.org/protect/PROTECTION/3b66c39e1.pdf>. Acesso em janeiro de 2009.

22 Ver artigos $2^{\circ}$ e $3^{\circ}$ da Convenção sobre a Proteção dos Direitos de Todos os Trabalhadores Migrantes e Suas Famílias.

23 Disponível em: <http://www.un.org/unrwa/>. Acesso em janeiro de 2009.

24 Quadro esquemático apresentado por Liliana Lyra Jubilut em: JUBILUT, Liliana Lyra, Migrações e Desenvolvimento, em AMARAL JR., Alberto do (org.), Direito Internacional e Desenvolvimento (São Paulo: Manole, 2005, p. 123-54).

25 Disponível em: <http://www.unhcr.org/protect/PROTECTION/43ce1cff2.pdf>. Acesso em 2009.

26 Para mais detalhes a respeito do tema, ver: FOSTER, Michelle, International Refugee Law and Socio-Economic Rights: Refuge from Deprivation (Cambridge: Cambridge University Press, 2007).

27 Disponível em: <http://www2.ohchr.org/english/law/rtd.htm>. Acesso em janeiro de 2009. 


\section{REFERÊNCIAS BIBLIOGRÁFICAS}

CHOLEWINSKI, Ryszard; PERRUCHOUD, Richard; MACDONALD, Euan (Eds.). International migration law: developing paradigms and key challenges. Hage: T.M.C. Asser Press, 2007.

EL-HINNAWI, Esam. Environmental refugees, 4. ed. Nairobi: UNEP, 1985.

FELLER, Erika. Asylum, migration and refugee protection: realities, myths and the promise of things to come. International Journal of Refugee Law, v. 18, n. 3-4, p. 509-36, 2006.

FISCHEL DE ANDRADE, J. H. Direito internacional dos refugiados: evolução histórica (1921-1952). Rio de Janeiro: Renovar, 1996.

FOSTER, Michelle. International refugee law and socio-economic rights: refuge from deprivation. Cambridge: Cambridge University Press, 2007.

JUBILUT, Liliana Lyra. Migrações e desenvolvimento. In: AMARAL JR., Alberto do (Org.). Direito internacional e desenvolvimento. São Paulo: Manole, 2005. p. 123-54.

O direito internacional dos refugiados e sua aplicação no ordenamento jurídico brasileiro. São Paulo: Método, 2007.

LOPEZ, Aurelie. The protection of environmentally-displaced persons in International Law, v. 37, p. 365-409, 2007. Disponível em: <http://www.lclark.edu/org/envtl/objects/37-4_Volume_Index.pdf>. Acesso em janeiro de 2009. MCADAM, Jane. Book reviews, international migration law: developing paradigms and key challenges. International Journal of Refugee Law, v. 19, n. 4, p. 776-9, 2007.

Complementary protection and Beyond: how States deal with human rights protection. United Nations High Commissioner for Refugees. Working Paper n. 118, 2005.

MCCUE, Gregory S. Environmental Refugees: applying International Environmental Law to involuntary migration. Georgetown International Environmental Law Review, v. 6, p. 151-2, 1993.

KOZOLL, Christopher. Poisoning the well: persecution, the environment, and refugee status. Colorado Journal of International Environmental Law and Policy, v. 15, p. 271-2, 2004.

OLIVEIRA, Silvia Menicucci de. O direito ao desenvolvimento: teorias e estratégias de implementação. 2006. Tese (Doutor em Direito Internacional) - Faculdade de Direito, Universidade de São Paulo, São Paulo, 2006.

Av. Dr. João Beraldo, 1075 Bairro Saúde - 37550-000 Pouso Alegre - MG - Brasil uljubilutigmail.com

\section{Liliana Lyra Jubilut}

MESTRE E DOUTORA E EM DIREITO INTERNACIONAL Pela Universidade de São Paulo (USP)

LL.M EM INTERNATIONAL LEGAL STUDIES PELA NEW YORK UNIVERSITY SCHOOL OF LAW (EUA) PROFESSORA DE DIREITO INTERNACIONAL na Faculdade de Direito do Sul de Minas

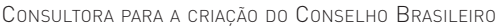
PARA Refugiados e fol AdVogada do CENTRO DE ACOLHIDA para Refugiados da CÁritas Arquidiocesana de São Paulo

EM PARCERIA COM O ACNUR E O GOVERNO BRASILEIRO

\section{Silvia Menicucci. O. S. Apolinário}

SEPN 707/907, Campus do Uniceub - FAJS, Bloco 3 Asa Norte - 70790-075 Brasília - DF - Brasil silmenicuccilahotmail.com
MESTRE E DOUTORA E EM DIREITO INTERNACIONAL PELA Universidade de SÃo PaUlo (USP)

PROFESSORA DE DIREITO INTERNACIONAL NO UNICEUB

Ex-advogada do Centro de Acolhida para Refugiados DA CÁRITAS ARQuIdIOCESANA dO RIO DE JANEIRO EM PARCERIA COM O ACNUR E O GOVERNO BRASILEIRO 